\title{
The effects of adding the aluminum sulfate to the urea formaldehyde adhesive applied on plywood
}

\author{
Murat Ozalp ${ }^{1}$, Hasan Kabak ${ }^{2}$, Abdi Atilgan ${ }^{3}$ and Hüseyin Peker ${ }^{4 *}$
}

\begin{abstract}
${ }^{1}$ Department of Furniture and Decoration Education, Dumlupinar University, 43500 Simav-Kutahya, Turkey. ${ }^{2}$ Department of Furniture and Decoration, Giresun University, Giresun Vocational School, 28048, Giresun-Turkey. ${ }^{3}$ Department of Furniture and Decoration, Artvin Coruh University, Artvin Vocational School, 08000, Artvin-Turkey.

${ }^{4}$ Department of Forest Industrial Engineering, Artvin Coruh University, 08000, Artvin-Turkey.
\end{abstract}

Accepted 8 April, 2013

\begin{abstract}
In the present study, the effects of adding the aluminum sulfate to the urea-formaldehyde (UF) adhesive, on the bonding characteristics and free formaldehyde content, have been studied. Experiments were conducted on the three layered plywood of ekaba (Tetraberlinia bifoliolata) and poplar (Populus $x$ eureamericana), prepared by adding aluminum sulfate to the adhesive mixtures of these tree species in certain amounts. Further, in the produced plywoods, the bending strength for BS EN 310, the withdrawal shear strength for BS EN 314-2, and free formaldehyde content for ENV 717-2 were analyzed, and the obtained results were compared. It was seen that the addition of aluminum sulfate to the adhesive mixture used on the plywood increased its bending strength and withdrawal shear strength, but reduced the free formaldehyde content significantly.
\end{abstract}

Key words: Bending strength, aluminum sulfate, free formaldehyde content, plywood.

\section{INTRODUCTION}

Plywood, particleboard and Medium Density Fiberboard (MDF) are widely used for making indoor products, such as, sub flooring, core panels of doors, and for furniture (Bodalal et al., 2000). The emission of formaldehyde is an important factor in the evaluation of the environmental and health effects of the wood-based board materials (Sundman et al., 2007). Formaldehyde is produced industrially in large quantities and used in many applications. It is also produced as a consequent of the reaction between ozone and terpenoid in the indoor environment (Nicolas et al., 2007). The health problems caused by air pollution in residential buildings have become a matter of increasing concern. Pollutants, such as, formaldehyde and acetaldehyde are emitted into the indoor environment from the building material and the construction products (Wanner, 1993). The major anthropogenic sources that affect humans in the indoor environment are products that contain formaldehyde, such as resins, glues, insulating material, oriented strand board (OSB), plywood, and fabrics (Singer et al., 2006). The effect of formaldehyde and volatile acetic acid emissions on the plywood that is treated with borax and boric acid were investigated. Borax had a decreasing effect on formaldehyde emission, whereas, boric acid had an increasing effect on it (Colakoglu and Çolak, 2004). A study conducted to analyze the properties of the OSB produced with phenol formaldehyde resin, revealed that the application of borax or zinc borate on the strands did not significantly alter the properties of the board (Donmez and Kalaycioglu, 2006). It is seen that the emissions of Volatile Organic Compounds (VOCs) can emanate from any material that creates a panel; until recently wide attention has been paid on the emission of formaldehyde emanating from the urea-formaldehyde (UF) adhesive 
(Baumann et al., 2000). The application of natural compounds, such as, urea, catechin, and vanillin could provide a simple and effective approach for suppressing the formaldehyde emission emanating from plywood (Uchiyama et al., 2007). It has also been observed that the addition of boric acid to melamine-urea-formaldehyde adhesive increased the adhesive strength in laminated veneer lumber (LVL) boards (Bridaux et al., 2001). The effects of boron treatment on the mechanical, biological, and dimensional properties of wood and wood-based material has been widely investigated. The measurement recorded through the desiccator method showed that formaldehyde emission emanating from plywood panels decreased when infused with borax (Colakoglu and Demirkir, 2006). The effect of adding borax pentahydrate to UF adhesive on the bonding characteristics of plywood and its free formaldehyde content has been studied. The addition of borax pentahydrate did not statistically affect the bending strength and withdrawal shear strength of the plywood, but it did reduce its free formaldehyde content (Sensogut et al., 2009). It has been observed that adding the powder of waste PET bottles and borax pentahydrate in equal amounts to ureaformaldehyde significantly increased the strength properties of plywood bonded using that resin. In addition, a moderate reduction in the free formaldehyde content was also recorded (Ozalp, 2010). The effects of borax pentahydrate addition to UF on the bonding characteristics and free formaldehyde content were investigated. Addition of borax pentahydrate to the adhesive mixture did not statistically affect the bending strength and tensile strength perpendicular to the plane of the fiberboard, but did reduce the free formaldehyde content (Ozalp, 2010).

The aim of the present study was to investigate the effects of the aluminum sulfate on the free formaldehyde content of urea-formaldehyde adhesive which is used in the production of plywood. This study also aspired to determine the ideal mixture ratio of the aluminum sulfate and adhesive by studying the effect of the different ratios of the mixture on the mechanical characteristics of the material.

\section{MATERIALS AND METHODS}

\section{Wooden material}

For the experiments, the veneers constructed from poplar (Populus $x$ eureamericana) and ekaba (Tetraberlinia bifoliolata) tree species were used as wooden material for plywood production. To ensure that the veneers revealed the chemical and biological characteristics of the tree species, they were constructed from the same lumber for both types of trees.

\section{The adhesive used}

Urea-formaldehyde (UF) adhesive was used in the production of plywood. This adhesive is used in $90 \%$ of the total production of wooden boards, as it requires a short setting duration in the hot- press, is easy to use and inexpensive, and has a transparent color. Technical characteristics of the urea-formaldehyde adhesive are like those; manufacturer is Polisan Chemical Industry Comp., commercial name is urea-formaldehyde 2265, molar ratio (urea/formaldehyde) is 1.35 , solid material rate (wt\%) is $55 \pm 1$, density $\left(\right.$ at $20^{\circ} \mathrm{C}$ ) is 1.22 to $1.23\left(\mathrm{~g} / \mathrm{cm}^{3}\right)$, viscosity (at $20^{\circ} \mathrm{C}$ ) is 100 to 200 (cps), $\mathrm{pH}$ (at $20^{\circ} \mathrm{C}$ ) is 7.5 to 8.5 , free formaldehyde (\%) is 0.8 max, storage time (at $20^{\circ} \mathrm{C}$ ) is 90 (days).

Approximately $180\left(\mathrm{~g} / \mathrm{m}^{2}\right)$ of adhesive (double glue line) was applied on the surface of the sample by means of a rolling press. UF adhesive with a 55 wt \% of solid content was used in the production of the test plywood. $15 \mathrm{wt} \%$ of ammonium chloride $\left(\mathrm{NH}_{4} \mathrm{Cl}\right)$, used as a hardening agent, was added to the liquid adhesive in a ratio of $10 \mathrm{wt} \%$. Wheat flour was also added to the adhesive as an additive, in a ratio of $55 \mathrm{wt} \%$ of the solid material. Aluminum sulfate was added as a modification agent to the adhesive in ratios of 5,10 , and $20 \mathrm{wt} \%$ of the total solid material. Aluminium sulfate, alternatively spelt aluminium sulphate, or aluminum sulphate, is a chemical compound with the formula $\mathrm{Al}_{2}\left(\mathrm{SO}_{4}\right)_{3}$. Aluminium sulfate is mainly used as a flocculating agent in the purification of drinking water and waste water treatmentplants, and also in paper manufacturing. Aluminium sulfate is sometimes incorrectly referred to as alum but alums are closely related compounds typified by $\mathrm{KAI}\left(\mathrm{SO}_{4}\right)_{2} \cdot 12 \mathrm{H}_{2} \mathrm{O}$ (Kvech and Edwards, 2002).

The anhydrous form occurs naturally as a rare mineral millosevichite, found e.g. in volcanic environments and on burning coal-mining waste dumps. Aluminium sulfate is rarely, if ever, encountered as the anhydrous salt. It forms a number of different hydrates, of which the hexadecahydrate $\mathrm{Al}_{2}\left(\mathrm{SO}_{4}\right)_{3} \cdot 16 \mathrm{H}_{2} \mathrm{O}$ and octadecahydrate $\mathrm{Al}_{2}\left(\mathrm{SO}_{4}\right)_{3} \cdot 18 \mathrm{H}_{2} \mathrm{O}$ are the most common. The heptadecahydrate, whose formula can be written as $\left[\mathrm{Al}\left(\mathrm{H}_{2} \mathrm{O}\right)_{6}\right]_{2}\left(\mathrm{SO}_{4}\right)_{3} \cdot 5 \mathrm{H}_{2} \mathrm{O}$, occurs naturally as the mineral alunogen. Aluminium sulfate is used in water purification and as a mordant in dyeing and printing textiles. In water purification, it causes impurities to coagulate which are removed as the particulate settles to the bottom of the container or more easily filtered. This process is called coagulation or flocculation. When dissolved in a large amount of neutral or slightly-alkaline water, aluminium sulfate produces a gelatinous precipitate of aluminium hydroxide, $\mathrm{Al}(\mathrm{OH})_{3}$. In dyeing and printing cloth, the gelatinous precipitate helps the dye adhere to the clothing fibers by rendering the pigment insoluble. Aluminium sulfate is sometimes used to reduce the $\mathrm{pH}$ of garden soil, as it hydrolyzes to form the aluminium hydroxide precipitate and a dilute sulfuric acid solution. An example of what changing the $\mathrm{pH}$ level of soil can do to plants is visible when looking at the Hydrangea macrophylla. The gardener can add aluminium sulfate to the soil to reduce the $\mathrm{pH}$ level which in turn will result in the flowers of the Hydrangea turning a different color.

Aluminium sulfate is the active ingredient of some antiperspirants; however, beginning in 2005 the US Food and Drug Administration no longer recognized it as a wetness reducer. Aluminium sulfate is usually found in baking powder, where there is controversy over its use due to concern regarding the safety of adding aluminium to the diet. In construction industry it is used as waterproofing agent and accelerator in concrete. Another use is a foaming agent in fire fighting foam. It is also used in styptic pencils, and pain relief from stings and bites. It can also be very effective as a molluscicide, killing spanish slugs. Some technical characteristics belonging to utilized aluminium sulfate are given in Table 1.

In the experiments conducted to analyze the bending strength of the plywood, the BS EN 310 rules were followed (BS EN 310, 1993). The samples to be examined (20 replicates) were prepared in such a manner that they measured $150 \mathrm{~mm}$ in length and $50 \mathrm{~mm}$ in width and the length axis was parallel to the fiber direction of the exterior layers. The samples were then acclimatized in the air conditioning cabin at a temperature of $20^{\circ} \mathrm{C}$ and a relative humidity 
Table 1. Properties of the aluminium sulfate (Patnaik, 2002).

\begin{tabular}{ll}
\hline Molecular formula & $\mathrm{Al}_{2}\left(\mathrm{SO}_{4}\right)_{3}$ \\
\hline Molar mass & $342.15 \mathrm{~g} / \mathrm{mol}$ (anhydrous), $666.42 \mathrm{~g} / \mathrm{mol}$ (octadecahydrate) \\
Appearance & white crystalline solid, hygroscopic \\
Density & $2.672 \mathrm{~g} / \mathrm{cm}^{3}$ (anhydrous), $1.62 \mathrm{~g} / \mathrm{cm}^{3}$ (octadecahydrate) \\
Melting point & $770^{\circ} \mathrm{C}\left(\right.$ decomp, anhydrous), $86.5^{\circ} \mathrm{C}$ (octadecahydrate) \\
Solubility in water & $31.2 \mathrm{~g} / 100 \mathrm{ml}\left(0^{\circ} \mathrm{C}\right), 36.4 \mathrm{~g} / 100 \mathrm{ml}\left(20^{\circ} \mathrm{C}\right), 89.0 \mathrm{~g} / 100 \mathrm{ml}\left(100^{\circ} \mathrm{C}\right)$ \\
Solubility & slightly soluble in alcohol, dilute mineral acids \\
Acidity & 3.3 to 3.6 \\
\hline
\end{tabular}

Table 2. Values of the bending strength and the withdrawal-shear strength $\left(\mathrm{N} / \mathrm{mm}^{2}\right)$.

\begin{tabular}{|c|c|c|c|c|c|c|c|c|c|}
\hline \multirow{3}{*}{ Type of tree } & \multirow{3}{*}{ Values } & \multicolumn{4}{|c|}{ Values of bending strength } & \multirow{2}{*}{\multicolumn{4}{|c|}{$\begin{array}{c}\text { Values of withdrawal-shear strength } \\
\text { The aluminum sulfate ratio (wt\%) }\end{array}$}} \\
\hline & & The & uminum & fate rati & (t \%) & & & & \\
\hline & & 0 & 5 & 10 & 20 & 0 & 5 & 10 & 20 \\
\hline \multirow{4}{*}{ Ekaba } & Max. & 100.97 & 101.34 & 101.70 & 103.56 & 13.21 & 13.48 & 13.71 & 14.35 \\
\hline & Min. & 95.80 & 96.04 & 97.50 & 98.35 & 12.60 & 12.63 & 12.78 & 12.92 \\
\hline & Average & 98.52 & 99.09 & 99.60 & 101.01 & 12.89 & 12.98 & 13.31 & 13.80 \\
\hline & Stand. Dev. & 1.44 & 1.32 & 1.22 & 1.65 & 0.18 & 0.23 & 0.35 & 0.41 \\
\hline \multirow{4}{*}{ Poplar } & Max. & 79.30 & 81.36 & 83.39 & 83.87 & 9.86 & 10.30 & 10.62 & 11.48 \\
\hline & Min. & 70.32 & 71.68 & 73.06 & 78.09 & 9.42 & 9.73 & 9.75 & 10.20 \\
\hline & Average & 76.06 & 76.80 & 78.32 & 81.22 & 9.67 & 9.96 & 10.13 & 10.83 \\
\hline & Stand Dev. & 2.92 & 2.81 & 3.02 & 1.81 & 0.14 & 0.18 & 0.29 & 0.38 \\
\hline \multicolumn{2}{|c|}{ Sample number } & 20 & 20 & 20 & 20 & 20 & 20 & 20 & 20 \\
\hline
\end{tabular}

of $65 \%$. The following method was used to calculate the bending strength of the sample.

$\sigma_{\mathrm{e}}=\frac{3 \cdot \mathrm{F} \cdot \mathrm{L}}{2 \cdot \mathrm{b} \cdot \mathrm{a}^{2}}$

Where $\sigma_{e}$ : Bending strength $\left(\mathrm{N} / \mathrm{mm}^{2}\right), \mathrm{F}$ : Maximum force noted at the moment of breakage $(\mathrm{N}), \mathrm{L}$ : Distance between the points of support $(\mathrm{mm})$, B: Width of the sample piece $(\mathrm{mm})$, a: Thickness of the sample piece $(\mathrm{mm})$.

In the experiments conducted to ascertain the withdrawal-shear strength, BS EN 314-2 regulations were followed (BS EN 314-2, 1993). The samples to be studied (20 replicates) measured 100 $\mathrm{mm}$ in length and $25 \mathrm{~mm}$ in width and were prepared in such a manner that their length axis was parallel with the fiber direction of the exterior layers. Subsequently, they were acclimatized at a temperature of $20^{\circ} \mathrm{C}$ and a relative humidity of $65 \%$ in the air conditioning cabin. The following equation was applied for the calculation of the withdrawal-shear strength.

$\sigma_{\mathrm{w}}=\frac{\mathrm{F}}{\mathrm{A}}=\frac{\mathrm{F}}{(\mathrm{b} . \mathrm{l})}$

Where $\sigma_{\mathrm{w}}$ : Withdrawal-shear strength $\left(\mathrm{N} / \mathrm{mm}^{2}\right), F$ : Maximum force noted at the moment of breakage $(\mathrm{N}), \mathrm{b}$ : Width of the sample in cross-section $(\mathrm{mm})$, I: Length of the sample in cross-section $(\mathrm{mm})$. Measurements were conducted in the experiment laboratory of the quality control management department of Kastamonu integrated
Comp. in Kastamonu, Turkey to calculate the free formaldehyde content (in 3 replicates). The experiments were conducted in accordance with the EN 717-2 standard (EN 717-2, 1994).

\section{The production of the experiment samples}

In order to manufacture a three-layered plywood constituting dimensions of $80 \times 80 \times 0.4(\mathrm{~cm})$, poplar and ekaba veneers of outer layers measuring $1.1(\mathrm{~mm})$ and mid layer measuring $2.2(\mathrm{~mm})$ were used. The boards were pressed in the $150 \times 300(\mathrm{~cm})$ press area of an electric heated hydraulic press used in the plywood factory. The pressure of the press area was set at $10\left(\mathrm{~kg} / \mathrm{cm}^{2}\right)$ and the temperature was set at $110^{\circ} \mathrm{C}$ in accordance with the standards. The duration for pressing was taken to be $5 \mathrm{~min}$.

\section{RESULTS AND DISCUSSION}

The results of the analyses carried out to study the bending strength and withdrawal-shear strength of plywood

The average values of the bending strength and withdrawal-shear strength of the poplar and ekaba plywood produced to determine the effect of adding the aluminum sulfate to the adhesive mixture in varying ratios are given in Table 2. It is evident that the values of 
Table 3. Results of the bending strength variance analysis.

\begin{tabular}{lccccc}
\hline Variance source & Df & Sum of squares & Mean squares & F test & P \\
\hline Type of tree & 1 & 18410.729 & 18410.729 & 3820.207 & 0.000 \\
Aluminum sulfate ratio (wt\%) & 3 & 334.882 & 111.627 & 23.163 & 0.000 \\
Error & 155 & 746.992 & 4.819 & & \\
Total & 159 & 19492.602 & & & \\
\hline
\end{tabular}

Table 4. Results of the withdrawal-shear strength variance analysis.

\begin{tabular}{lccccc}
\hline Variance source & Df & Sum of squares & Mean squares & F test & P \\
\hline Type of tree & 1 & 383.387 & 383.387 & 4445.827 & 0.000 \\
Aluminum sulfate ratio (wt \%) & 3 & 24.519 & 8.173 & 94.775 & 0.000 \\
Error & 155 & 13.366 & 0.086 & & \\
Total & 159 & 421.272 & & & \\
\hline
\end{tabular}

Table 5. Values of the free formaldehyde content.

\begin{tabular}{|c|c|c|c|c|}
\hline \multirow{3}{*}{ Type of tree } & \multirow{3}{*}{ Values } & \multicolumn{3}{|c|}{ Formaldehyde content $(\mathrm{mg} / \mathbf{1 0 0} \mathrm{g})$} \\
\hline & & \multicolumn{3}{|c|}{ The aluminum sulfate ratio (wt \%) } \\
\hline & & 0 & 10 & 20 \\
\hline \multirow{4}{*}{ Ekaba } & Max. & 75.01 & 65.87 & 63.14 \\
\hline & Min. & 73.45 & 64.05 & 62.19 \\
\hline & Average & 74.26 & 64.75 & 62.62 \\
\hline & Stand. Deviation & 0.78 & 0.97 & 0.48 \\
\hline \multirow{5}{*}{ Poplar } & Max. & 72.98 & 52.13 & 49.94 \\
\hline & Min. & 71.98 & 50.89 & 48.97 \\
\hline & Average & 72.51 & 51.39 & 48.98 \\
\hline & Stand Deviation & 0.50 & 0.65 & 0.54 \\
\hline & Sample Number & 3 & 3 & 3 \\
\hline
\end{tabular}

bending strength and withdrawal-shear strength of the ekaba plywood are higher than values of the poplar plywood. However, adding the aluminum sulfate to the adhesive increases the values of bending strength and the withdrawal-shear strength of both types of samples significantly. The interaction between these obtained values was examined by means of the variance analysis and the results obtained are given in Tables 3 and 4 . According to the results of the variance analysis, the effect of aluminum sulfate to the adhesive mixture of poplar and ekaba plywood on both the bending strength and withdrawal-shear strength of the plywood was found to be significant with a $5 \%$ margin of error.

The results of the analysis carried out to study the free formaldehyde content in plywood

The content data for free formaldehyde are given in Table 5. It clearly indicates that adding the aluminum sulfate to the adhesive mixture results in decreasing the content of free formaldehyde in plywood. It is seen that the values of free formaldehyde content of the ekaba plywood are higher than the values of the poplar plywood, and adding the aluminum sulfate to the adhesive decreases the value of free formaldehyde content of both types of samples to a certain amount. The interaction between these obtained values was examined by means of the variance analysis and the obtained results are given in Table 6. According to the results of the variance analysis, the effect of adding the aluminum sulfate to the adhesive mixtures of both poplar and ekaba plywood on the free formaldehyde content was found to be quite significant with a $5 \%$ margin of error.

\section{Conclusion}

It has been observed that adding the powder of the aluminum sulfate to urea formaldehyde significantly 
Table 6. Results of the free formaldehyde content variance analysis.

\begin{tabular}{lccccc}
\hline Variance source & Df & Sum of squares & Mean squares & F test & P \\
\hline Type of tree & 1 & 403.753 & 403.753 & 40.457 & 0.000 \\
Aluminum sulfate ratio (wt \% ) & 2 & 1085.222 & 542.611 & 54.370 & 0.000 \\
Error & 14 & 139.719 & 9.980 & & \\
Total & 17 & 1628.694 & & & \\
\hline
\end{tabular}

increased the strength properties of plywood bonded by using this resin. In addition, a moderate reduction in the free formaldehyde content was also recorded. Due to the fact that formaldehyde emissions hold a significant importance for human health, aluminum sulfate, which decrease the levels of this emission and increase the strength properties of plywood, must preferably be used in building material.

\section{REFERENCES}

Baumann MGD, Lorenz LF, Batterman SA, Zhang GZ (2000). Aldehyde Emissions from particleboard and medium density fiberboard products. For. Prod. J. 50(9):75-82.

Bodalal A, Zhang JS, Plett EG (2000). A method for measuring internal diffusion and equilibrium partition coefficients of volatile organic compounds for building materials. Build. Environ. 35:101-10.

Bridaux V, Charrier B, Fauroux N, Charrier F, Gonzalez J (2001). Addition of boron based compound in the LVL glueline: Effect on the mechanical properties and the leaching of boron. Holzforschung. 55:5.

BS EN 310 (1993). Wood-based panels. Determination of modulus of elasticity in bending and of bending strength, 1993.

BS EN 314-2 (1993). Plywood - Bonding quality Part 2: Requirements (R).

Colakoglu G, Colak S (2004). Volatile acetic acid and formaldehyde emission from plywood treated with boron compound. Build. Environ. 39:533-536.

Colakoglu G, Demirkir C (2006). Characteristics of plywood panels produced with urea formaldehyde resin containing borax. Holz als Roh- und Werkstoff. 64:250-251.

Donmez A, Kalaycioglu H (2006). Some technological features of the oriented strand boards OSB) produced with borax. III. Int. Boron Symposium. P. 117.
EN 717-2 (1994). Wood-based panels- Determination of formaldehyde release-Part1: Formaldehyde emission by the gas analysis method.

Kvech S, Edwards M (2002). "Solubility controls on aluminum in drinking water at relatively low and high $\mathrm{pH}^{\prime \prime}$. Water Res. 36(17):4356-4368.

Nicolas M, Ramalho O, Maupetit F (2007). Reactions between ozone and building products: Impact on primary and secondary emissions. Atmos. Environ. pp. 3129-3138.

Ozalp M (2010). Study of the effect of adding the powder of waste PET bottles and borax pentahydrate to the urea formaldehyde adhesive applied on plywood. Eur. J. Wood Prod. 69:369-374.

Ozalp M (2010). The effect of borax pentahydrate addition to urea formaldehyde on the mechanical characteristics and free formaldehyde content of medium density fiberboard (MDF). Eur. J. Wood Prod. 68:117-119.

Patnaik P (2002). Handbook of Inorganic Chemicals. McGraw-Hill, ISBN 0070494398.

Sensogut C, Ozalp M, Yesil H (2009). The effect of borax pentahydrate addition to urea formaldehyde on the mechanical characteristics and free formaldehyde content of plywood. Int. J. Adhesion Adhesives 29(5):589-592. ISSN: 0143-7496.

Singer BC, Coleman BK, Destaillats H, Hodgson AT, Lunden MM, Weschler CJ, Nazaroff WW (2006). Indoor secondary pollutants from cleaning product and air freshener use in the presence of ozone. Atmos. Environ. 40:6696-6710.

Sundman MR, Larsen A, Vestin E, Weibull A (2007). Formaldehyde emission-Comparison of different standard methods. Atmos. Environ. 41:3193-3202.

Uchiyama S, Matsushima E, Kitao N, Tokunaga $H$, Ando M, Otsubo $Y$ (2007). Effect of natural compounds on reducing formaldehyde emission from plywood. Atmos. Environ. 41:8825-8830.

Wanner HU (1993). Sources of pollutants in indoor air. IARC Sci. Pub. 09:19-30. 